\title{
THE CLINICAL FEATURES OF ATRIOVENTRICULAR CANAL DEFECT
}

\author{
Andriana Malska \\ Department of Propedeutics of Pediatrics and Medical Genetics \\ Danylo Halytskyy Lviv National Medical University \\ 69 Pekarska str., Lviv, Ukraine, 79010
}

\begin{abstract}
Atrioventricular canal defect (AVCD) is a congenital heart defect, which occurs in $2.9 \%$ of all congenital heart defects (CHD) and is characterized by a wide variety of anatomical forms and often don't have clear cardiac manifestation. Untreated AVCD may lead to the development of pulmonary hypertension.

Aim. To determine clinical features of AVCD in children, considering variable anatomical forms of the pathology and its association with genetic pathology.

Materials and methods. Patients history and outpatient statistic records of children with AVCD, who were admitted to Lviv Regional Children's Hospital from September 1999 till January 2016 have been analyzed ( $n=84)$.

The aspects of clinical manifestation of AVCD without associated pathology have been identified ( $\mathrm{n}=48$ ). Clinical manifestation of complete $(n=36)$ and incomplete $(n=12)$ AVCD and clinical manifestation with and without Down syndrome have been discussed.

Children with AVCD were divided into two groups: A - children with complete ( $\mathrm{n}=36)$ and B - with incomplete $(\mathrm{n}=12)$ form of AVCD. Group A was divided into A1 - with trisomy 21 ( $\mathrm{n}=14)$, A2 - without genetic pathology ( $\mathrm{n}=22$ ).

Results. In group A2 - 36,36 $\pm 10,26 \%$ and in group B - 50 $14,4 \%$ children were asymptomatic. Dyspnea, increased sweating during feeds, growth retardation and frequent respiratory viral infections during early childhood period were leading symptoms. Most frequent auscultation findings were accent of II heart sound over the pulmonary artery and 2-3/6 systolic murmur over left sternal border. According to echocardiographic examination mitral valve insufficiency was predominantly of mild grade, tricuspid

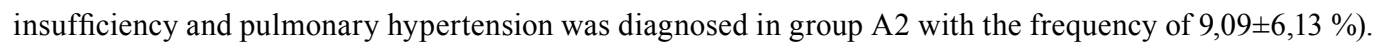

Conclusions: The absence of clinical features in group A2 and B 36,36 $\pm 10,26$ and 50,00 $\pm 14,40$ respectively, saturation levels $92,36 \pm 0,49 \%$ in patients without genetic pathology and 95,25 $\pm 0,40 \%$ with incomplete AVCD provide a need to adopt protocol of children examination with saturation level under $95 \%$ and compulsory echocardiographic diagnosis within the first month of life.

Keywords: Atrioventricular canal defect, complete and incomplete AVCD, trisomy 21, echocardiography, trisomy 21.
\end{abstract}

\section{Introduction}

According to WHO data 4-5\% of the newborns are diagnosed with congenital or hereditary pathology annually [1]. Nearly $2 \%$ of them are diagnosed with severe anomalies inconsistent with life and primarily with congenital heart defects [2]. Almost $40 \%$ of the early childhood mortality partially or completely is caused by hereditary diseases and half of them are the cardiac system pathology [3].

Nearly 28-30 000 children are born in Lviv region annually and nearly 220-280 are diagnosed with CHD [4]. Cardiac defects are among the leading cause of the childhood mortality and disability [5].

\section{Aim of research}

To determine clinical features of various forms of atrioventricular canal defect (AVCD) in children with and without genetic pathology.

\section{Materials and methods}

Patients history and outpatient statistic records of the children with AVCD, who were admitted to Lviv Regional Children's Hospital in the period of September 1999 - January 2016 have been analyzed $(n=84)$. Patient history, clinical features, chest X-ray, Ekg and echocardiography data have been included in the research. 
Clinical features of the defect were determined in children without associate pathology $(\mathrm{n}=48)$. Children were divided into two groups $-\mathrm{A}-$ children with complete form of atrioventricular canal defect $(n=36)$, and B - children with incomplete AVCD $(n=12)$. Group A was divided into two groups: A1 - children with complete form of AVCD and trisomy 21 ( $n=14)$, A2 - children with complete form and without genetic pathology, respectively $(n=22)$.

Gained results were gathered in the table in absolute numbers with the following mathematical calculation on a personal computer with the "Microsoft Excel" and "Statistica" programs used.

During the medical statistical analysis the mean and its standard deviation $(\mathrm{M} \pm \sigma)$, relative values, reliability and likelihood differences among analyzed groups were estimated.

The normality check proved Gaussian type distribution data, therefore in the binary comparison the Student's T-criteria, and in frequency comparison - xi-square were applied.

\section{Results}

According to the research it was determined, that children with AVCD had eight main clinical features. They were most frequently seen in children with complete form and with trisomy 21 (group A1); asymptomatic children were observed in group A2 - B 36,36 $\pm 10,26 \%$ and $50 \pm 14,4 \%$, respectively (Table 1).

Therefore, children with complete form of AVCD and with trisomy 21 (group A1) the most frequently diagnosed clinical features were tachypnea, sweating during feeding (in $100 \%$ ), growth retardation (in 78,57 $\pm 11,00 \%$ ), failure to thrive and frequent respiratory tract infections $(50,00 \pm 13,40 \%$ ).

Most frequent clinical features in children with complete form of ACD without genetic pathology (group A2) were failure to thrive $(50,00 \pm 10,66 \%)$ and growth retardation $(40,91 \pm 10,48 \%)$, tachypnea and excessive sweating during feeds $(36,36 \pm 10,26 \%)$.

Children with incomplete form of AVCD 9 group B) most frequently had: recurring respiratory tract infections in their medical history $(41,67 \pm 14,20 \%)$, tachypnea and excessive sweating during feeds $(33,33 \pm 13,60 \%)$, and failure to thrive $(25,00 \pm 12,50 \%)$. Absence of clinical features was seen in group A2 and B - 36,36 $\pm 10,26$ and 50,00 $\pm 14,40$ respectively.

Table 1

Frequency (\%) of clinical features in children with AVCD

\begin{tabular}{|c|c|c|c|c|}
\hline \multirow{2}{*}{ № } & \multirow{2}{*}{ Clinical features } & \multicolumn{3}{|c|}{ Groups } \\
\hline & & A1 & A2 & B \\
\hline 1 & Tachypnea, excessive sweating during feeds & 100 & $36,36 \pm 10,26^{* *}$ & $33,33 \pm 13,60 * *$ \\
\hline 2 & Growth retardation & $78,57 \pm 11,00$ & $40,91 \pm 10,48$ & $25,00 \pm 12,50 * *$ \\
\hline 3 & Failure to thrive & $50,00 \pm 13,40$ & $50,00 \pm 10,66$ & $25,00 \pm 12,50$ \\
\hline 4 & Recurrent respiratory tract infections & $50,00 \pm 13,40$ & $27,27 \pm 9,50$ & $41,67 \pm 14,20$ \\
\hline 5 & Aggravated cardiac heave & $21,43 \pm 11,00$ & $13,64 \pm 7,32$ & $25,00 \pm 12,5$ \\
\hline 6 & Cyanosis & $14,29 \pm 9,40$ & 0 & 0 \\
\hline 7 & Enlarged chest cage & $7,14 \pm 6,90$ & 0 & 0 \\
\hline 8 & Heart hump formation & $7,14 \pm 6,90$ & 0 & 0 \\
\hline 9 & Absence of clinical features & 0 & $36,36 \pm 10,26^{* *}$ & $50,00 \pm 14,40 * *$ \\
\hline
\end{tabular}

Note: $* *$ - reliable $(p<0,01)$ difference is present in comparison with group A1 
Auscultation data was analyzed as well. In children with complete AVCD and trisomy 21 (Group A1) were accentuated second heart sound of the pulmonary artery (PA) (in $71,43 \pm 12,10 \%$ ) and $2 / 6$ on the Levine scale systolic murmur over the left sternal border $(57,14 \pm 13,20 \%)$. Children with complete AVCD without genetic pathology (group A2) had the same auscultation findings, although less frequently (Table 2).

In children with incomplete form of AVCD the most frequent auscultation findings were $-1-2 / 6$ systolic murmur over the left sternal border $(58,33 \pm 14,20 \%)$ and a soft second tone accent over the PA $(41,67 \pm 14,20 \%)$.

\section{Table 2}

Auscultation data (\%) in children with AVCD

\begin{tabular}{|c|c|c|c|c|}
\hline \multirow{2}{*}{ № } & \multirow{2}{*}{ Auscultation data } & \multicolumn{3}{|c|}{ Groups } \\
\hline & & A1 & $\mathbf{A 2}$ & B \\
\hline 1 & Systolic murmur over the left upper sternal border & $21,43 \pm 11,00$ & $36,36 \pm 10,26$ & $33,33 \pm 13,60$ \\
\hline 2 & Systolic murmur over the left sterna border & $57,14 \pm 13,20$ & $50,00 \pm 10,66$ & $58,33 \pm 14,20$ \\
\hline 3 & No auscultation findings & $21,43 \pm 11,00$ & 0 & $33,33 \pm 13,60$ \\
\hline 4 & $1 \backslash 6$ & 0 & $27,27 \pm 9,50$ & $16,67 \pm 10,80$ \\
\hline 5 & $2 \backslash 6$ & $57,14 \pm 13,20$ & $40,91 \pm 10,48$ & $25,00 \pm 12,50$ \\
\hline 6 & $3 \backslash 6$ & 0 & $13,64 \pm 7,32$ & $25,00 \pm 12,50$ \\
\hline 7 & $4 \backslash 6$ & $7,14 \pm 6,90$ & 0 & 0 \\
\hline 8 & $\mathrm{~S} 2$ accent over PA & $71,43 \pm 12,10$ & $59,09 \pm 10,48$ & $41,67 \pm 14,20$ \\
\hline 9 & Holosystolic murmur over the left sternal border & 0 & $4,55 \pm 4,44$ & $8,33 \pm 8,00$ \\
\hline
\end{tabular}

During percussion, reliable $(\mathrm{p}<0,01)$ in groups of children with complete AVCD - the widening of the heart borders to the right $(92,86 \pm 6,90$ in group A1 and 90,91 $\pm 6,13$ in group A2), in comparisson with the group B, where this indication constituted 41,67 $\pm 14,20 \%$. Simultaneously, the widening of the heart borders to the left most frequently was seen in children with incomplete form of AVCD, however there was no reliable difference in those parameters in groups of children with complete AVCD (Table 3).

Table 3

Percussion data (\%) in children with AVCD

\begin{tabular}{llccc}
\hline № & Percussion data & Groups & A2 & B \\
\hline 1 & Widening to the right & $92,86 \pm 6,90 £ £$ & $90,91 \pm 6,13 £ £$ & $41,67 \pm 14,20$ \\
2 & Widening to the left & 0 & $4,55 \pm 4,44$ & $8,33 \pm 8,00$
\end{tabular}

Note: $£ £$ - reliable difference $(p<0,01)$ is present in comparison with group $B$ 
It was established that the middle level of the saturation (Fig. 1) was reliably $(\mathrm{p}<0,01)$ lower

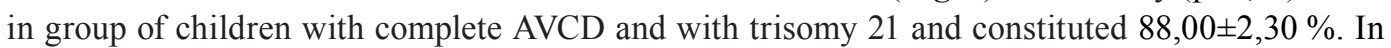
patients without genetic pathology it was in the range of $92,36 \pm 0,49 \%$, and in children with incomplete AVCD - 95,25 $\pm 0,40 \%$.

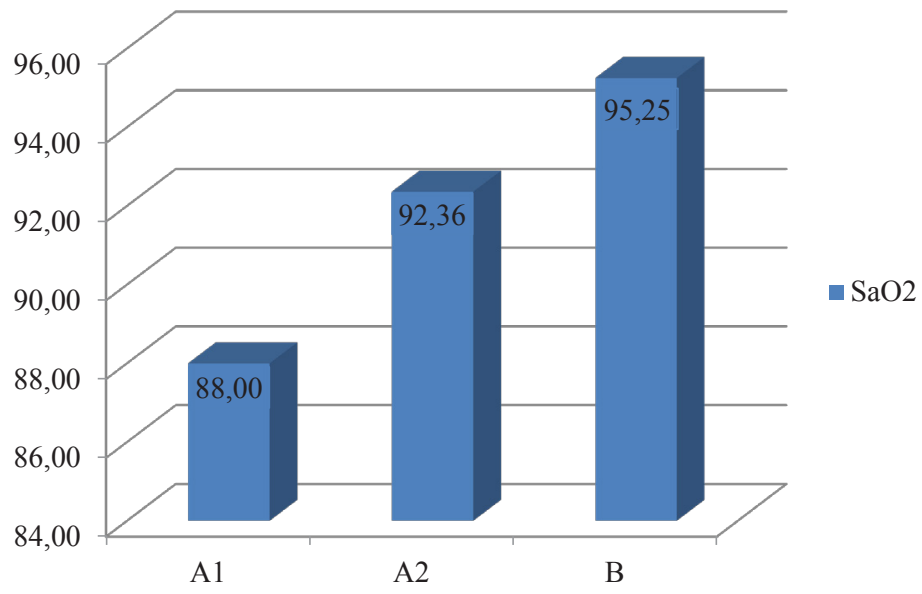

Fig. 1. Average saturation levels (\%) in children within three groups in children with AVCD

During the analysis of internal organs ultrasound - no pathology was diagnosed. Rarely (9\%) it was combined with lowered and horseshoe kidney and hepatomegaly. It is worth mentioning that only children without associated pathology were included into the research. Therefore AVCD was not associated with any internal pathology in our research (Table 4).

Table 4

Internal organs ultrasound data (\%) in children with AVCD

\begin{tabular}{|c|c|c|c|c|}
\hline \multirow{2}{*}{ № } & \multirow{2}{*}{ Ultrasound data } & \multicolumn{3}{|c|}{ Groups } \\
\hline & & A1 & A2 & B \\
\hline 1 & No pathological findings & 100 & $90,91 \pm 6,13$ & $91,67 \pm 8$ \\
\hline 2 & Lowered right kidney & 0 & 0 & $8,33 \pm 8$ \\
\hline 3 & Horseshoe kidney & 0 & $4,55 \pm 4,44$ & 0 \\
\hline 4 & Hepatomegaly & 0 & $4,55 \pm 4,44$ & 0 \\
\hline
\end{tabular}

According to EKG data, sinus rhythm was present in all groups and only in the group of children with complete AVCD without genetic pathology 4,55 $\pm 4,44 \%$ the first degree heart block was diagnosed. The right bundle branch block was diagnosed in $-33,33 \pm 13,60 \%$ in the group of children with incomplete AVCD (Table 5).

According to Echocardiography data in children with complete AVCD associated with trisomy $21-78,57 \pm 11,00 \%$ prevailed balanced form and in the group without genetic pathology (A2) balanced form was met in $90,91 \pm 6,13 \%$ of children.

In Table 6 it is shown that pulmonary hypertension was more frequently diagnosed in the group A1, however the IV stage of PH was diagnosed in $9,09 \pm 6,13 \%$ children with complete form of AVCD without genetic pathology. 
Table 5

EKG findings (\%) in children with AVCD

\begin{tabular}{ccccc}
\hline № & EKG findings & \multicolumn{2}{c}{ Groups } \\
\hline 1 & Sinus rhythm & A1 & A2 & B \\
\hline 2 & I-st degree AV block & 100 & $95,45 \pm 4,44$ & 100 \\
3 & Leftward axis deviation & 0 & $4,55 \pm 4,44$ & 0 \\
4 & Rightward axis deviation & 100 & $95,45 \pm 4,44$ & $91,67 \pm 8,00$ \\
5 & Right heart chambers hypertrophy & 0 & $4,55 \pm 4,44$ & $8,33 \pm 8,00$ \\
6 & RBBB & 100 & $95,45 \pm 4,44$ & 100
\end{tabular}

Table 6

Echocardiography data (\%) in children with AVCD

\begin{tabular}{|c|c|c|c|c|}
\hline \multirow{2}{*}{ № } & \multirow{2}{*}{ Echocardiography data } & \multicolumn{3}{|c|}{ Groups } \\
\hline & & A1 & $\mathbf{A 2}$ & B \\
\hline 1 & I degree $\mathrm{PH}$ & $14,29 \pm 9,4$ & $13,64 \pm 7,32$ & $8,33 \pm 8,00$ \\
\hline 2 & II degree PH & $35,71 \pm 12,80$ & $4,55 \pm 4,44$ & 0 \\
\hline 3 & III degree PH & $7,14 \pm 6,90$ & 0 & 0 \\
\hline 4 & IV degree $\mathrm{PH}$ & 0 & $9,09 \pm 6,13$ & 0 \\
\hline 5 & Right chambers volume overload & $92,86 \pm 6,90$ & $68,18 \pm 9,93^{*}$ & $33,33 \pm 13,60^{* * \#}$ \\
\hline 6 & ASD I (mm) & $8,93 \pm 1,00$ & $9,55 \pm 0,73$ & $11,67 \pm 1,30$ \\
\hline 7 & VSD & $9,21 \pm 1,40$ & $5,05 \pm 0,63 \#$ & $5,50 \pm 2,50$ \\
\hline 8 & Bulging aneurysm & 0 & 0 & $8,33 \pm 8,00$ \\
\hline 9 & Single av valve & $28,57 \pm 12,10$ & $13,64 \pm 7,32$ & $0 *$ \\
\hline 10 & Unique atrium & $7,14 \pm 6,90$ & 0 & 0 \\
\hline 11 & AV valve insufficiency & $7,14 \pm 6,90$ & $9,09 \pm 6,13$ & 0 \\
\hline 12 & Clefted anterior mitral leaflet & $64,29 \pm 12,80$ & $68,18 \pm 9,93$ & $100 * \#$ \\
\hline 13 & Mitral valve insufficiency $1+$ (mild) & $78,57 \pm 11,00$ & $77,27 \pm 8,93$ & $66,67 \pm 13,60$ \\
\hline 14 & Mitral valve insufficiency $2+$ (moderate) & $7,14 \pm 6,90$ & $9,09 \pm 6,13$ & $8,33 \pm 8,00$ \\
\hline 15 & Mitral valve insufficiency $3+$ (severe) & 0 & 0 & $8,33 \pm 8,00$ \\
\hline 16 & Tricuspid valve insufficiency $1+$ (mild) & $28,57 \pm 12,10$ & $31,82 \pm 9,93$ & $0 * \#$ \\
\hline 17 & Tricuspid valve insufficiency $2+$ (moderate) & 0 & $4,55 \pm 4,44$ & $8,33 \pm 8,00$ \\
\hline 18 & Single atrium & $14,29 \pm 9,40$ & 0 & 0 \\
\hline 19 & Deformed anterior leaflet & 0 & $4,55 \pm 4,44$ & 0 \\
\hline 20 & Aorta $(\mathrm{cm})$ & $1,22 \pm 0,10$ & $1,41 \pm 0,09$ & $1,46 \pm 0,10$ \\
\hline 22 & Pulmonary Artery (cm) & $1,41 \pm 0,10$ & $1,51 \pm 0,08$ & $1,53 \pm 0,10$ \\
\hline 23 & $\mathrm{EF} \%$ & $70,07 \pm 0,90$ & $69,18 \pm 0,81$ & $69,58 \pm 0,50$ \\
\hline
\end{tabular}

Note: * - reliable difference $(p<0,05)$ in comparison with group A1; **-reliable difference $(p<0,01)$ in comparison with group A1; $\#$ - reliable difference $(p<0,05)$ in comparison with group A2; \#\#-reliable difference $(p<0,01)$ in comparison with group A2 
Insignificant $(\mathrm{p}<0,05)$ right chambers volume overload was diagnosed in children with incomplete AVCD $(33,33 \pm 13,60 \%)$, whereas in children with complete AVCD - 68,18 $\pm 9,93 \%$ in group A2 and in $92,86 \pm 6,90 \%$ - in group A1.

Single AV valve was not diagnosed in children with incomplete AV canal, whereas (100\%) had clefted anterior mitral valve leaflet.

Mild mitral valve insufficiency was diagnosed in all groups, whereas moderate and severe was observed much rarely. Mild tricuspid insufficiency in groups with complete form of AVCD prevailed in the A2 group; moderate tricuspid insufficiency was met in the group A2 and B.

According to the chest $\mathrm{x}$-ray data, the aggravation of the pulmonary fields, widened vascular bundle and widened PA is more common for all groups of children with CAVCD (Table 7).

Table 7

Chest X-ray data (\%) in children with AVCD

\begin{tabular}{|c|c|c|c|c|}
\hline \multirow{2}{*}{ № } & \multirow{2}{*}{ Chest $x$-ray data } & \multicolumn{3}{|c|}{ Groups } \\
\hline & & A1 & A2 & B \\
\hline 1 & Cardiomegaly & $28,57 \pm 12,10$ & $13,64 \pm 7,32$ & $8,33 \pm 8,00$ \\
\hline 2 & increased pulmonary pattern & 100 & 100 & $91,67 \pm 8,00$ \\
\hline 3 & Pulmonary fields without focal and infiltrative shadows & 0 & 0 & $8,33 \pm 8,00$ \\
\hline 4 & Overlapping PA & $14,29 \pm 9,40$ & $4,55 \pm 4,44$ & 0 \\
\hline 5 & KTI \% & $55,86 \pm 1,00$ & $55,41 \pm 1,05$ & $53,18 \pm 1,10$ \\
\hline 7 & Unchanged vascular bundle & 0 & 0 & $8,33 \pm 8,00$ \\
\hline 8 & Widened vascular bundle & 100 & $90,91 \pm 6,13$ & $58,33 \pm 14,20 * \#$ \\
\hline 9 & Flattened waist of the heart & 0 & 0 & $8,33 \pm 8,00$ \\
\hline
\end{tabular}

\section{Discussion}

According to the official data, the amount of congenital heart defects has increased significantly as well as its role in the cause of the newborn mortality. Congenital heart defects are the reason of the newborn mortality in $15 \%$ of the cases [6]. Nearly $40 \%$ of the children with congenital heart defects die without surgery, and nearly $70 \%$ of them die during the first days of life and the $30 \%$ die during the first year of life, respectively [7].

AVCD constitutes 3-5\% in the structure of all of the congenital heart defects [7-9], however according to fetal echo-cardiography the frequency of AVCD may be up to $17 \%$ [10]. Heterotaxy syndrome is combined with AVCD in $80 \%$ (more frequently asplenia rather then polysplenia $[2,3]$. Children with trisomy 21 have congenital heart defect and in $40 \%$ of the cases it is AVCD (the complete form prevails) $[3,6,10]$. According to the molecular mapping it is considered that the part of the 21-st chromosome 21q22.1-qter could be linked to the impairment of the endocardial cushions development $[6,11]$.

AVCD is characterized by a wide variety of its anatomical forms and as a rule, does not have a typical for a congenital heart defect early clinical manifestation [12]. This contributes to the difficulties of early clinical diagnosis of the following CHD, which is crucial in terms of definition of the terms of the surgical correction of the defect [13]. 
Parents of the most of children with AVCD do not have any complaints, therefore the disease can be suspected by a pediatrician during the random visit for a checkup. Depending on a size of VSD doctor could auscultate 1-3/6 systolic murmur over the left sternal border and a typical Ekg should be helping in diagnosing this defect $[14,15]$.

AVCD - is a complex congenital heart defect which is characterized by the anomalous connection on the ventricular and atrial level due to the common atrioventricular canal, which occurs due to the endocardial cushions defect $[16,17]$. In the process of embryogenesis endocardial cushions form two atrioventricular valves and participate in the end stage of the septum formation. Therefore the defect of the embryogenesis caused by different factors leads to septal and two separate valve (mitral and trileaflet) and cusps formation defection [18-20].

\section{Conclusions}

1. Children with AVCD are not often manifested clinically, and the risk of developing pulmonary hypertension is high, the necessity of creating a protocol of clinical diagnosis of this congenital heart defect is well-grounded.

2. Echocardiography remains a golden standard of diagnosis of AVCD, especially in children with trisomy 21.

3. Saturation level has to be checked at the maternity hospital. Children with the saturation level lower than $95 \%$ have to undergo echocardiography examination in the early neonatal period.

\section{References}

[1] Calabro, R., Limongelli, G. (2006). Complete atrioventricular canal.Orphanet Journal of Rare Diseases, 1 (1), 8. doi: 10.1186/1750-1172-1-8

[2] Allen, H. D., Driscoll, D. J., Shaddy, R. E., Feltes, T. F. (2008). Moss and Adam's Heart Disease in Infants, Children, and Adolescents: Including the Fetus and Young Adults. Philadelphia: Lippincott Williams \& Wilkins, 1680.

[3] Crawford, M. H., DiMarco, J. P., Paulus, W. J. et. al. (2010). Cardiology. Mosby. Ch. 117. Atrioventricular Canal Defects, 1561-1571.

[4] Main Administration of the Statistics in Lviv Region (2015). Statistic data. Report «Population 1995-2015 year», 1 .

[5] Hoffman, J. I., Kaplan, S. (2002). The incidence of congenital heart disease. Journal of the American College of Cardiology, 39 (12), 1890-1900. doi: 10.1016/s0735-1097(02)01886-7

[6] Abdulla, R. (2011). Heart Diseases in Children: A Pediatrician's Guide. Berlin: Springer, 123-132. doi: 10.1007/978-1-4419-7994-0

[7] Anderson, R. H., Baker, E. J., Penny, D., Redington, A. N., Rigby, M. L., Wernovsky, G. (2010). Paediatric Cardiology. Ch. 8-9. Amsterdam: Elsevier Ltd., 1327. doi: 10.1016/b978-0-7020-3064-2.00073-4

[8] Acar, P., Laskari, C., Rhodes, J., Pandian, N., Warner, K., Marx, G. (1999). Three-dimensional echocardiographic analysis of valve anatomy as a determinant of mitral regurgitation after surgery for atrioventricular septal defects. The American Journal of Cardiology, 83 (5), 745-749. doi: 10.1016/s00029149(98)00982-5

[9] Barnett, J. V., Desgrosellier, J. S. (2007). TGF $\beta$ Signaling During Atrioventricular Cushion Transformation. Ch. 13. Cardiovascular Development and Congenital Malformations, 55-58. doi: 10.1002/9780470988664.ch13

[10] Lymarenko, M. P., Logvynenko, N. G., Artyuch, T. V. (2009). Atriovantricular communication as a most frequent defect in children with Down Syndrome. Ukrainian cardiology journal, 4, 77-81.

[11] Baron, M. G., Wolf, B. S., Steinfeld, L., Van Mierop, L. H. S. (1964). Endocardial cushion defects. The American Journal of Cardiology, 13 (2), 162-175. doi: 10.1016/0002-9149(64)90171-7

[12] Bonow, R. O., Carabello, B. A., Chatterjee, K., de Leon, A. C., Faxon, D. P., Freed, M. D. et. al. (2006). ACC/AHA 2006 Guidelines for the Management of Patients With Valvular Heart Disease. Journal of the American College of Cardiology, 48 (3), e1-e148. doi: 10.1016/j.jacc.2006.05.021

[13] Hoohenkerk, G. J., Bruggemans, E. F., Rijlaarsdam, M., Schoof, P. H., Koolbergen, D. R., Hazekamp, M. G. (2010). More than 30 years' experience with surgical correction of atrioventricular septal defects. The Annals of Thoracic Surgery, 90 (5), 1554-1561. doi: 10.1016/j.athoracsur.2010.06.008 
[14] Ongley, P. A., Pongpanich, B., Spangler, J. G., Feldt, R. H.; Feldt, R. H. (Ed.) (1976). The electrocardiogram in atrioventricular canal. Atrioventricular canal defects. Philadelphia: WB Saunders, 51.

[15] Barratt-Boyes, B. G., Neutze, J. M., Harris, E. A. (Eds.) (1973). Correction of atrioventricular canal defects in infancy using profound hypothermia. In Heart disease in infancy: diagnosis and surgical treatment. Edinburgh: Churchill Livingstone, 110.

[16] Cheng, H.-L., Huang, C.-H., Tsai, H.-E., Chen, M.-Y., Fan, S.-Z., Hsiao, P.-N. (2012). Intraoperative Assessment of Partial Atrioventricular Septal Defect with a Cleft Mitral Valve by Real-Time Three-Dimensional Transesophageal Echocardiography. Anesthesia \& Analgesia, 114 (4), 731-734. doi: 10.1213/ ane.0b013e3182468db3

[17] Machlitt, A., Heling, K.-S., Chaoui, R. (2004). Increased cardiac atrial-to-ventricular length ratio in the fetal four-chamber view: a new marker for atrioventricular septal defects. Ultrasound in Obstetrics and Gynecology, 24 (6), 618-622. doi: 10.1002/uog.1750

[18] Jegatheeswaran, A., Pizarro, C., Caldarone, C. A., Cohen, M. S., Baffa, J. M., Gremmels, D. B. et. al. (2010). Echocardiographic definition and surgical decision-making in unbalanced atrioventricular septal defect: a Congenital Heart Surgeons' Society multiinstitutional study. Circulation, 122 (11), S209-S215. doi: 10.1161/circulationaha.109.925636

[19] Kogon, B. E., Butler, H., McConnell, M., Leong, T., Kirshbom, P. M., Kanter, K. R. (2007). What is the optimal time to repair atrioventricular septal defect and common atrioventricular valvar orifice? Cardiology in the Young, 17 (04), 356. doi: 10.1017/s1047951107000856

[20] Lacour-Gayet, F., Comas, J., Bruniaux, J., Serraf, A., Losay, J., Petit, J. et. al. (1991). Management of the left atrioventricular valve in 95 patients with atrioventricular septal defects and a common atrioventricular orifice-a ten year review. Cardiology in the Young, 1 (04), 367-373. doi: 10.1017/s104795110001043x 